\title{
Blossom blight caused by Botrytis cinerea on Camellia japonica in Brazil
}

\author{
Wagner Vicente Pereira ${ }^{1}$ (D) Louise Larissa May-De Mio ${ }^{1}$
}

Received: 1 May 2019 / Accepted: 27 August 2020 / Published online: 1 September 2020

(C) Società Italiana di Patologia Vegetale (S.I.Pa.V.) 2020

Keywords Ornamental disease $\cdot$ Variegata cultivar $\cdot$ Botrytis $\cdot$ Multigenic phylogeny

In November 2018, flowers of twelve-plants of Camellia japonica L. of the Variegata cultivar with blossom blight symptoms ( $80 \%$ incidence) were observed in Curitiba, Paraná. The symptoms on the petals were water-soaked lesions of light brown color that developed into dark brown necrotic lesions and growth of mycelium with gray spores. Fragments of the lesioned petals were disinfected, deposited into Potato-Dextrose-Agar and stored at $25{ }^{\circ} \mathrm{C}$ for 20 days. The five isolates obtained showed aerial mycelial growth of gray color after 3-days of cultivation. Sclerotia $(2.3-7.5 \times 1.7-$ $5.0 \mathrm{~mm}$ ), produced after 20 days of cultivation, were black, spherical or irregular. Conidia $(n=50)$ were unicellular, ovoid to ellipsoid, light brown and measured 9.8-16.8 $\times 5.9$ $10.1 \mu \mathrm{m}$. Conidiophores were erect, dark brown and presented 18 to $29 \mu \mathrm{m}$ in length. For molecular identification, the ITS region, G3PDH and RPB2 genes of one isolate (LEMIDCJ02) were sequenced as described by Staats et al. (2005). The sequences obtained (GenBank accession Nos. MK852638, MK868051 and MK868052) showed 100\% similarity with B. cinerea (MH860108, MF461630, and MH796662). Multigenic phylogenetic analysis based on Bayesian inference showed that isolate had clustered within the clade of
B. cinerea. To evaluate the pathogenicity, a conidia suspension containing $10^{5}$ conidia $\mathrm{mL}^{-1}$ of the LEMIDCJ02 isolate was sprayed on 10 healthy flowers attached in plants to the point of runoff. Another 10 flowers received water and were used as controls. After inoculation, the flowers were covered with plastic bags containing moistened cotton to provide a humid chamber. Seven days after inoculation, typical symptoms appeared in all inoculated flowers and no symptoms in the control flowers. The pathogen was re-isolated and presented the same characteristics of the isolate used in inoculation. To our knowledge, this is the first official report of blossom blight in Camellia japonica caused by B. cinerea in Brazil.

\section{References}

Staats M, van Baarlen P, van Kan JA (2005) Molecular phylogeny of the plant pathogenic genus Botrytis and the evolution of host specificity. Mol Biol Evol 22:333-346

Publisher's note Springer Nature remains neutral with regard to jurisdictional claims in published maps and institutional affiliations.

Wagner Vicente Pereira

wvpereira@hotmail.com

1 Departamento de Fitotecnia e Fitossanidade, Universidade Federal do Paraná, Curitiba, Paraná, Brazil 